\section{LA DESOBEDIENCIA CIVIL EN LA CAMPAÑA LA OBRA SOCIAL DE LA PAH}

\author{
Marina Pera Ros \\ Universitat Autònoma de Barcelona \\ ORCID iD: http://orcid.org/0000-0002-6478-8728 \\ mp3266@columbia.edu
}

Cómo citar este artículo/Citation: Pera Ros, M. (2019). La desobediencia civil en la campaña la obra social de la PAH. Arbor, 195 (793): a517. https://doi.org/10.3989/arbor.2019.793n3005

Recibido: 12 febrero 2016. Aceptado: 31 marzo 2016.

RESUMEN: Este artículo analiza los factores que llevaron a personas sin activismo político previo a participar en la campaña del movimiento de la Plataforma de Afectados por la Hipoteca (PAH) la obra social de la PAH. El contexto del estudio es la crisis hipotecaria, con más de 580.000 ejecuciones hipotecarias en el Estado español entre 2009 y 2015. A través del análisis de entrevistas semi-estructuradas, los resultados muestran cómo los interlocutores construyen un relato legitimador de la desobediencia civil como última opción en una serie de protestas por el derecho a la vivienda. Haber sido desahuciado, no tener dónde vivir y la incapacidad del Estado para ofrecer vivienda social son algunas de las razones justificativas expuestas por los entrevistados. Al final suelen mostrar su voluntad de cumplir con las obligaciones ciudadanas y pagar un alquiler social según sus ingresos.

PALABRAS CLAVE: Ocupación a causa de la pobreza; movimientos sociales; desobediencia civil; acción colectiva; legitimidad.

\section{CIVIL DISOBEDIENCE IN THE CAMPAIGN OF THE PAH SOCIAL PROGRAM}

Copyright: (C) 2019 CSIC. Este es un artículo de acceso abierto distribuido bajo los términos de la licencia de uso y distribución Creative Commons Reconocimiento 4.0 Internacional (CC BY 4.0).
ABSTRACT: This paper examines the factors that led people without previous political activism to take part in the campaign of the PAH's (Plataforma de Afectados por la Hipoteca). The context of this study is the mortgage crisis that led more than 580,000 foreclosures in Spain from 2009 to 2015. The analysis of the semi-structured interviews shows that interviewees build narratives that legitimize the use of civil disobedience as the final protest action to reclaim social housing. Having been evicted, with no place to live and the state's inability to protect and fulfil their rights to housing are just some of the reasons given by interviewees to join the PAH. Finally, the interviewees embrace a discourse of good citizenship, showing their will to legalize their situation through affordable rent payment according to their income.

KEYWORDS: Deprivation based squatting; social movements; civil disobedience; collective action; legitimacy. 


\section{INTRODUCCIÓN AL MERCADO DE LA VIVIENDA EN EL ESTADO ESPAÑOL Y EN CATALUÑA}

El mercado de alquiler de viviendas en el Estado español está por debajo de la media europea. Las causas de esta inferioridad de arrendamientos se remontan medio siglo atrás (Alguacil Denche et al., 2013). Durante las décadas de 1950 y 1960, la creciente inmigración desde las áreas rurales a las ciudades llevó a la construcción de nuevas viviendas mayoritariamente en régimen de propiedad. Después, en 1970 y 1980, se promovió entre las nuevas construcciones la propiedad por encima del alquiler a través de descuentos fiscales a los propietarios y a los titulares de hipotecas. Siguiendo esta senda, en 1996, los incentivos fiscales se extendieron a segundas y a terceras viviendas (Cabré Pla y Módenes Cabrerizo, 2004).

En 1998 hubo un punto de inflexión en la historia de la vivienda en el Estado español, con la aprobación de la ley del suelo. Esta ley llevó a la liberalización de las recalificaciones del suelo y se transfirieron las competencias de urbanización de este a las comunidades autónomas y a los gobiernos locales, sin mecanismos de control. De este modo, el nuevo contexto desembocó en un auge de la construcción de nuevos edificios; de las 200.000 viviendas iniciadas al año durante el período 1990-1995 se pasó a las 400.000 en 1998 y a las 500.000 al año entre 1999 y 2003, llegando al máximo con más de 650.000 durante el período 2004-2007 (Alguacil Denche et al., 2013). Cabe notar que entre 1998 y 2008 el precio de las viviendas se incrementó casi un 180\% (Palomera, 2014).

Con relación al derecho a la vivienda y a las políticas para desarrollarlo, en 1978 la nueva constitución española incluía el derecho a la vivienda en el artículo $47^{1}$. Aunque se edificó vivienda social, mayoritariamente de protección oficial, la cantidad no fue suficiente para cubrir la demanda; además era fundamentalmente de propiedad y la categoría de protección oficial tenía habitualmente una temporalidad finita, hecho que propició las reventas de inmuebles a precios de mercado (Pareja Eastaway y Sánchez Martínez, 2012).

Otro factor importante en esta investigación es la ley hipotecaria vigente, escrita y aprobada en 1946 durante la dictadura franquista. Entonces las hipotecas no estaban tan extendidas y eran pactadas por períodos cortos. En el año 2000 se produjo otro hecho relevante: el gobierno español alteró la ley estableciendo que los titulares de las hipotecas pasarían a ser plenamente responsables de la totalidad de la deuda aunque no pudieran pagarla y el banco hubiese embargado dicha propiedad, con la agravante de que la modificación también establecía intereses de demora y costas judiciales.

En los casos en que los titulares contrataran una hipoteca por primera vez, o las hipotecas supusieran más del $80 \%$ del valor económico de la vivienda, era necesario tener avalistas. Estos avalistas podían pasar a ser responsables de la deuda en el caso de que los titulares no pudiesen pagar, como sucedió en muchos casos (Palomera, 2014).

La entrada del Estado español en la Unión Europea permitió a los bancos ofrecer créditos a un interés más bajo, al mismo tiempo que les llevó a vender más crédito para incrementar los beneficios (Naredo, 2009).

En 2008, cuando el mercado hipotecario de Estados Unidos entró en crisis, la economía española cayó en recesión. El incremento de precios en los inmuebles se detuvo y su venta empezó a disminuir. Dentro de este contexto, también la denominada economía real se resintió y la tasa de desempleo empezó a subir, llegando al 27,16\% en el primer trimestre de 2013 (véase Instituto Nacional de Estadística. Encuesta de población activa) y dificultando por ende el pago de hipotecas y alquileres.

La exclusión social debida a factores residenciales se incrementa (Alguacil Denche et al., 2013) y el fenomeno del sinhogarismo dificulta la participación de las personas en su entorno immediato, el acceso a ciertos derechos a través del padrón y el desarrollo de la socialización y la intimidad de la persona en el hogar (Sabaté, 2014). El sinhogarismo incluye, de acuerdo con la European Federation of National Organisations Working with the Homeless (FEANTSA), tanto la falta de un hogar y la pernoctación en el espació público como la precariedad habitacional; incluye también la falta de suministros básicos, subarriendo de habitaciones, ocupación de viviendas o vivir acogido en casa de familiares o amigos (Alguacil Denche et al., 2013). Así, la residencia se confirma como uno de los factores potenciadores de pertenencia al entorno inmediato (barrio, ciudad) que, en casos de pérdida o deterioro de la vivienda, deriva habitualmente en exclusión social, obstaculizando la participación y la integración en la sociedad (Sabaté, 2014).

Finalmente, el Consejo General del Poder Judicial publicó que entre 2009 y 2015 se realizaron 580.000 ejecuciones hipotecarias (véase Poder Judicial España. Consejo General del Poder Judicial. Estadística Judicial). No obstante, la Plataforma de Afectados por la Hipoteca (PAH) ha denunciado reiteradamente que la cantidad de deshaucios es mayor (Colau y Alemany, Enero 2013. 20072012: Retrospectiva sobre desahucios y ejecuciones hipotecarias en España, estadísticas oficiales e indicadores). 


\section{EL CASO DE ESTUDIO: LA OBRA SOCIAL DE LA PLATA- FORMA DE AFECTADOS POR LA HIPOTECA}

El movimiento social Ilamado Plataforma de Afectados por la Hipoteca surgió en Barcelona en febrero 2009 para apoyar a las personas en riesgo de ser desahuciadas. Se han formado grupos en diferentes ciudades y pueblos que por sí mismos se coordinan en reuniones periódicas, en las que los afectados explican su situación, y otras personas, en su mayor parte afectadas también, proponen acciones, comparten vivencias, así como su conocimiento burocrático y legal. En diciembre de 2015 había en Cataluña 78 grupos de la PAH constituidos (véase Cómo contactar con la $P A H$ ).

La finalidad de la PAH es la de trabajar por el derecho a una vivienda digna, denunciando la especulación y acumulación de inmuebles vacíos que ha caracterizado la expansión del urbanismo, sobre todo en la primera década del siglo XXI. Así, las acciones de la PAH apelan al derecho a la vivienda contemplado en el artículo 47 en la constitución española, y también en tratados internacionales como la carta de los derechos humanos.

La PAH ha desarrollado diferentes campañas. Cabe destacar una Iniciativa Legislativa Popular (ILP) para regular la dación en pago retroactiva y otros aspectos ${ }^{2}$, y también la campaña de escraches para presionar a los políticos del parlamento español contrarios a la dación en pago mediante la visualización pública de su posicionamiento. Otras campañas consisten en frenar los desahucios, invitando a la concentración de gente delante de la casa de la persona afectada en el momento en que el desahucio se lleva a cabo; así como la campaña de la vivienda social conocida como la obra social de la PAH. A su vez, se llevan a cabo acciones en marcos supralocales y supraestatales, como la denuncia de la ley hipotecaria española ante las Cortes europeas y el informe a la relatora especial de la ONU sobre el derecho a una vivienda digna, entre otras. En este entorno, la PAH ha conseguido parte de sus objetivos a corto y a medio plazo, como por ejemplo la sentencia del Tribunal de Justicia de la Unión Europea y del Tribunal de los Derechos Humanos de Estrasburgo dictaminado que la ley hipotecaria española es incompatible con la directiva de protección de los consumidores de 1993 y con el artículo 47 de la carta de los derechos fundamentales de la Unión Europea (Colau y Alemany, Enero 2013. 2007-2012: Retrospectiva sobre desahucios y ejecuciones hipotecarias en España, estadísticas oficiales e indicadores).
La campaña la obra social de la $P A H^{3}$, en la que esta centrado este análisis, se inició en 2011, cuando muchas de las personas desahuciadas no tenían dónde vivir. Es en este contexto en el que el discurso de la campaña florece, argumentando en primer lugar que la ley hipotecaria española establece o posibilita que, después de la pérdida del inmueble residencial, la deuda aún no quede cancelada, lo cual crea una situación de profunda vulnerabilidad. Además, el Estado o en el caso de Cataluña la Generalitat ${ }^{4}$ no dispone de suficientes viviendas sociales o centros de acogida para hospedar a todos los afectados, y se observa que en la mayoría de los casos las familias ni siquiera pueden asumir el coste de las viviendas sociales de protección oficial. Los bancos acumulan viviendas vacías que no se venden a causa de la crisis económica y las políticas públicas que obligan a las entidades financieras a alquilar esos inmuebles son escasas y de aplicación lenta.

El código civil español establece que la vivienda tiene una función social y que los edificios vacíos no están realizando dicha función. En este marco la campaña la obra social de la $P A H$ consiste en la ocupación de edificios vacíos que pertenecen a la Sociedad de Gestión de Activos Procedentes de la Reestructuración Bancaria (SAREB) ${ }^{5}$ para dar una función social a las viviendas vacías y recuperar así el derecho a la vivienda.

La campaña de la PAH ofrece los edificios vacíos a personas y familias vulnerables que no tienen alternativa habitacional, exigiendo a los gobiernos (el español, los regionales y los locales) y a los bancos una negociación para obtener un alquiler asequible para esas familias. La selección de los individuos se hace según criterios económicos y en función de sus posibilidades de encontrar alternativas habitacionales. Hay otros criterios, como la existencia de menores, que se acuerdan en cada núcleo de la $\mathrm{PAH}$. Las personas que entran a vivir en un edificio de la PAH necesitan acreditar sus ingresos y la ausencia de alternativas habitacionales a través de un informe de servicios sociales.

De 2011 a 2014 hubo 40 bloques de pisos ocupados y aproximadamente 3.000 personas realojadas en el Estado español; algunos bloques lograron el alquiler social ${ }^{6}$ mediante negociaciones con los bancos (véase Cómo contactar con la PAH). En Cataluña se ocuparon hasta 25 bloques en diferentes ciudades como Sabadell, Barcelona, Salt, Manresa y Terrassa.

Finalmente cabe mencionar y contextualizar la existencia del fenómeno okupa en Cataluña, anterior a la 
campaña de la PAH. Las referencias a este movimiento se registran en la década de 1980 y desde entonces arraiga, caracterizado por un alto grado de diversidad. Durante estas décadas los activistas del movimiento okupa son los principales actores que reclaman el derecho a la vivienda a partir de acciones visibles, tales como ocupaciones de inmuebles, de naves industriales, etc. Este movimiento tiene mayoritariamente un fuerte componente identitario y cerrado en sí mismo, con sus demandas políticas contra la propiedad privada y el sistema capitalista (Mir García, França, Macías y Veciana, 2013).

A mediados de la década de los 90, en toda Europa hay cambios significativos en el movimiento okupa, que se observan también en Cataluña. Este movimiento entra en contacto con otras reivindicaciones contemporáneas en auge, como el movimiento altermundista. El resultado de estos procesos influye en la apertura del movimiento okupa, que se va relacionando con las comunidades donde están albergados los inmuebles. Sin embargo, aún pesa el factor identitario en el movimiento y la diversidad dentro del tipo de okupaciones (Mir García et al., 2013).

\section{MÉTODOS DE INVESTIGACIÓN}

Dada la naturaleza de la pregunta de investigación, ¿cuáles son las razones que llevan a personas sin activismo político previo a participar en la campaña de ocupaciones colectivas la obra social de la PAH?, la metodología escogida fue la cualitativa, ya que permitía entender el fenómeno en su complejidad a través del análisis del discurso. Específicamente la técnica usada para la recogida de datos fue la entrevista semiestructurada, con preguntas abiertas.

La muestra consiste en dieciocho entrevistas a diecinueve personas mayores de edad, que participaban en el momento, que habían participado, o que habían ayudado a participar (en el caso del portavoz) en la campaña la obra social de la PAH. Se entrevisó a trece mujeres y a seis hombres de cinco ciudades de Cataluña: Salt, Blanes, Manresa, Sabadell y Barcelona. La selección de los informantes se realizó de manera que fuesen entrevistadas personas de género femenino y masculino, de los diferentes núcleos donde se habían dado las ocupaciones de la PAH y que no habían tenido experiencia en ningún tipo de movimiento social o entidad previamente, excepto el portavoz (véase la tabla 1).

En los casos de Salt y de Barcelona las personas ya no vivían en pisos ocupados, sino que habían conse- guido un alquiler social u ocupaban por su cuenta ${ }^{7}$. Por lo que refiere a Manresa y a Sabadell las personas entrevistadas vivían en bloques ocupados íntegramente como parte de la campaña. $Y$ en el caso de Blanes no eran bloques, sino pisos individuales repartidos por la ciudad.

Como se recoge en la tabla, de las personas entrevistadas catorce no estaban trabajando en la economía formal debido a diferents motivos y responsabilidades, desde el cuidado de los familiares dependientes hasta realizar un trabajo en el sector informal de la limpieza. Además, dos no trabajaban por motivos de enfermedad y cuatro tenían contrato pero este no era de jornada completa sino de media jornada o inferior. Algunas personas declararon trabajar ocasionalmente en la economía informal, pero eso no les suponía un ingreso estable ni suficiente para alquilar un piso a precio de mercado. De las personas en situación de paro algunas cobraban subsidios del Servicio Público de Empleo Estatal, otras estaban pendientes de la renta mínima de inserción de la Generalitat de Cataluña (PIRMI), y otras estaban sin ingresos de ningún tipo por el momento. La mayoría recibían alimentos por parte de alguna entidad social o a partir de la autoorganización en la PAH. Su nivel educativo era mayoritariamente primario o secundario y solo el portavoz tenía estudios universitarios.

La mayoría de las personas entrevistadas, concretamente catorce de diecinueve, tenían hijos conviviendo con ellas en los pisos ocupados. De las personas entrevistadas seis eran mujeres solas con sus hijos, que en la mayoría de casos no recibían la pensión correspondiente por parte de sus exparejas. Finalmente, en términos de inmigración, ocho de las personas entrevistadas eran nacidas fuera del Estado español, concretamente en países de Sudamérica y de África. Ninguna de las personas entrevistadas había estado previamente implicada en luchas sociales o en entidades reivindicativas (excepto el portavoz).

El objetivo de las entrevistas era analizar las experiencias de los interlocutores en la PAH y su discurso en torno a la legitimidad de las prácticas de desobediencia civil en las que estaban o habían estado implicados. Se ofreció anonimato a los interlocutores para protegerlos de represalias a causa de su implicación con las prácticas de desobediencia civil. En cuanto al lugar de la entrevista, fue generalmente en casa del entrevistado. 
Tabla 1. Datos de los informantes y situación de la deuda hipotecaria

\begin{tabular}{|c|c|c|c|c|c|c|}
\hline Informante & Pseudónimo & Género & Edad & $\begin{array}{l}\text { País de } \\
\text { origen }\end{array}$ & Ocupación & Situación de la hipoteca \\
\hline 1 & Gladys & $\mathrm{F}$ & 35 & Venezuela & $\begin{array}{l}\text { Limpieza pocas horas de } \\
\text { manera informal. }\end{array}$ & Dación en pago. \\
\hline 2 & Rosa & $\mathrm{F}$ & 47 & España & Parada. & $\begin{array}{l}\text { Deshauciada por impago } \\
\text { de alquiler. }\end{array}$ \\
\hline 3 & Eugenio & M & 46 & España & $\begin{array}{l}\text { A la espera de pensión de } \\
\text { invalidez. }\end{array}$ & $\begin{array}{l}\text { Deshauciado por impago } \\
\text { de alquiler. }\end{array}$ \\
\hline 4 & Sanae & $\mathrm{F}$ & 32 & Marruecos & Cuidado de sus hijos. & $\begin{array}{l}\text { Negociación con el banco } \\
\text { para conseguir dación en } \\
\text { pago. }\end{array}$ \\
\hline 5 & Martí & M & 33 & España & $\begin{array}{l}\text { Media jornada. Clases } \\
\text { particulares. }\end{array}$ & $\begin{array}{l}\text { No está afectado por } \\
\text { impago de hipoteca o } \\
\text { alquiler. }\end{array}$ \\
\hline 6 & Andrea & $\mathrm{F}$ & 34 & España & $\begin{array}{l}\text { Parada. A la espera de } \\
\text { recibir la renta mínima de } \\
\text { inserción. }\end{array}$ & $\begin{array}{l}\text { Deshauciada por impago } \\
\text { de alquiler. }\end{array}$ \\
\hline 7 & Juan & $\mathrm{M}$ & 50 & España & Parado. & Dación en pago. \\
\hline 8 & Isabel & $\mathrm{F}$ & 48 & España & $\begin{array}{l}\text { Limpieza en casas de } \\
\text { manera informal. }\end{array}$ & Dación en pago. \\
\hline 9 & Raúl & M & 41 & España & $\begin{array}{l}\text { Camarero durante } \\
\text { temporada de verano. }\end{array}$ & $\begin{array}{l}\text { Deshauciado por impago } \\
\text { de alquiler. }\end{array}$ \\
\hline 10 & Mónica & $\mathrm{F}$ & 32 & España & $\begin{array}{l}\text { Cuidado de su hijo de un } \\
\text { año. }\end{array}$ & $\begin{array}{l}\text { Deshauciado por impago } \\
\text { de alquiler. }\end{array}$ \\
\hline 11 & Dinora & $\mathrm{F}$ & 56 & Chile & Parada. & Dación en pago. \\
\hline 12 & Teresa & $\mathrm{F}$ & 57 & España & $\begin{array}{l}\text { Media jornada. } \\
\text { Administrativa. }\end{array}$ & Dación en pago. \\
\hline 13 & Fatou & $\mathrm{F}$ & 36 & Gambia & Cuidado de sus hijos. & $\begin{array}{l}\text { Negociación con el banco } \\
\text { para conseguir dación en } \\
\text { pago. }\end{array}$ \\
\hline 14 & Abbie & $\mathrm{F}$ & 37 & Gambia & Cuidado de sus hijos. & Dación en pago. \\
\hline 15 & Luis & M & 50 & España & Parado. & $\begin{array}{l}\text { Tramitación de la dación } \\
\text { en pago. }\end{array}$ \\
\hline 16 & Abdelhali & M & 18 & Marruecos & Parado. & $\begin{array}{l}\text { Deshauciado por impago } \\
\text { de alquiler. }\end{array}$ \\
\hline 17 & Hafida & $\mathrm{F}$ & 31 & Marruecos & Cuidado de sus hijos. & $\begin{array}{l}\text { Tramitación de la dación } \\
\text { en pago. }\end{array}$ \\
\hline 18 & Carmen & $\mathrm{F}$ & 37 & Bolivia & $\begin{array}{l}\text { Media jornada. Empresa } \\
\text { limpieza. }\end{array}$ & Dación en pago. \\
\hline
\end{tabular}

Fuente: Elaboración propia.

\section{MARCO TEÓRICO}

En este estudio se han usado diferentes teorías para aproximarnos al fenómeno estudiado en su complejidad. Ciertos elementos coyunturales como la crisis financiera global, la función social de la vivienda, el análisis del movimiento okupa en Europa y las teorías sobre los movimientos sociales son considerados explicativos para un posterior análisis del trabajo de campo desarrollado.

Harvey (2012) analiza la expansión de los mercados financieros y el proceso de urbanización global desde la perspectiva de denominación de clase. El geógrafo entiende el proceso de urbanización como una expansión de la plusvalía ${ }^{8}$, que la clase capitalista utiliza para invertir y maximizarla. De esta manera se cumple con la esencia del capitalismo: expansión constante para sobrevivir. En este sentido, el urbanismo ha servido desde el siglo XIX como sector estratégico para canalizar la inversión, para seguir con la expansión necesaria y para aumentar las ganancias (Lefèbvre, 2013). Saskia Sassen (2012), también desde una perspectiva marxista, analiza el sistema de deuda 
internacional y la expansión del mercado financiero a nivel global. Según Sassen (2012), el poder financiero explota a las personas, incluyendo la burguesía nacional de cada país. Desde la primera década del siglo $X X I$, el capitalismo financiero se ha ido expandiendo y ha ido ganando espacio al capitalismo productivo. La privatización del suelo, de la vivienda social, y la liberalización del mercado del suelo y de la vivienda forman parte de la acumulación primitiva necesaria en esta transición, forzando a las personas a adquirir créditos para poder acceder a un hogar.

Irene Sabaté (2014) analizó las diversas funciones sociales y los significados simbólicos de la vivienda. El lugar donde habitan los seres humanos es, en general, donde se desarrolla la intimidad, las actividades relacionadas con la higiene, el ocio, la socialización, el trabajo reproductivo y en algunos casos productivo y el almacenamiento de pertenencias. Los modelos de cohabitación son variados: viviendas con un solo núcleo familiar o con una sola persona, o con varios núcleos familiares o con varias personas sin vinculo familiar. La vivienda aporta también una relación con el exterior, tal como la interacción con los vecinos o la participación y el uso de los recursos de los barrios. Las características del hogar, las condiciones del inmueble, los recursos del barrio influyen en las posibilidades de acceder al mundo laboral y en el proceso de creación de identidades. Finalmente es necesario destacar la relación que existe entre el acceso a un hogar y los derechos de ciudadanía. El empadronamiento es habitualmente necesario para proceder a la solicitud de subsidios, al acceso a la educación o a la salud.

En la ausencia de un inmueble donde vivir, como serían los casos de desahucio o sinhogarismo, la pérdida afecta a los espacios donde se lleva a cabo parte de la vida diaria como ya se ha mencionado anteriormente, propiciando la exclusión social. Además, Sabaté (2014) ahonda en el análisis apuntando que, en los casos de desahucio debido al incumplimiento de los pagos de la hipoteca, se observa un sentimiento de culpa, de decepción por no haber sido capaz de pagar la deuda contraída, entendiendo la situación como un fracaso individual más que como un problema de correlación de factores de naturaleza estructural.

Con relación a las ocupaciones de viviendas en Europa, Hans Pruijt (2004) las analizó y categorizó. En esta investigación se utilizarán dos de sus categorías analíticas: la ocupación debida a la pobreza y la ocupación política.
Pruijt (2004) incica que la primera categoría es la más antigua en Europa y consiste en el uso de edificios vacíos sin el consentimiento del propietario por parte de individuos que por cuestiones económicas no podrán acceder a una vivienda. Señala que el perfil de personas susceptibles de participar en este tipo de ocupaciones ha ido variando con el tiempo pero tienen como patrón común el no tener otra alternativa para acceder a un hogar que ocupar, y el no tener otras problemáticas sociales, como podría ser una drogadicción, el uso habitual de la violencia física, etc. Algunos de los perfiles que han participado en estas ocupaciones son: personas inmigramtes sin papeles, familias sin techo, etc. En la mayoría de los casos, los ocupantes cuentan con la ayuda de activistas sociales en los momentos de apropiación del edificio y para el asesoramiento legal. Los inmuebles escogidos para ocupar suelen ser de titularidad pública o de un actor del que se espera cierta responsabilidad social. Las demandas políticas suelen centrarse en la obtención de una vivienda formalizada, en la denuncia de la ineficiencia política y en la infrautilización de edificios, pero no suelen orientarse hacia un cambio estructural del sistema político y económico.

La otra categoría de ocupación significativa para la investigación es la ocupación política, comúnmente conocida como okupación. Pruijt (2004) apunta que el objetivo de estas ocupaciones es construir un contra-poder al Estado para poder cuestionar el papel de este, pero también para cuestionar el marco ideológico del sistema político-económico. El autor también menciona que en este caso las acciones de ocupación no contemplan en general dentro de su repertorio la negociación con las autoridades políticas.

La desobediencia civil y su uso también es uno de los elementos esenciales que se estudian en esta investigación. John Rawls (1971) la definió como un acto no violento, realizado pública y conscientemente, donde se infringe una o varias leyes, con el objetivo de denunciar una normativa legal considerada injusta y promover un cambio de esta. Entonces los individuos implicados en un acto de desobediencia civil están dispuestos a aceptar las consecuencias legales que se deriven de la infracción.

En esta senda la justificación y la comunicación de las acciones de desobediencia civil tienen un rol crucial. Habitualmente la comunicación de las razones y de los derechos que se pretende defender con la acción transgresora busca llamar la atención, para posteriormente crear debate en torno a las demandas y así aumentar la presión hacia un cam- 
bio de políticas o de leyes. En ocasiones supone la interpelación a personas con capacidad ejecutiva y legislativa para que ofrezcan argumentos para mantener la ley cuestionada. Partiendo de la base de que la ciudadanía tiende a obedecer la ley, la desobediencia civil se ejerce después de haber recorrido los mecanismos legales a disposición. De acuerdo con Rawls (1971) esta estrategia de desacato parece más justificada cuando se han demandado cambios en el gobierno, estos no han prosperado y la situación se plantea como desesperante.

Finalmente, Tarrow (2011, p. 47) aporta una definición de movimiento social como grupo de individuos con propósitos comunes y solidaridad entre ellos que adoptan retos colectivos con una sostenida interacción con las élites y autoridades. Se parte de la idea de que, para conseguir sus objetivos, los movimientos sociales desarrollan un repertorio de acciones colectivas (Tilly, 1986). Esta variedad de actividades disponibles para perseguir sus fines queda condicionada por el contexto político y social y por las características del grupo que desarrolla la acción.

Gamson (1992) ya apuntó que el discurso de un movimiento social está influido por las acciones colectivas del movimiento, que dan sentido a sus objetivos y capacidades. Además, la acción colectiva da nueva información para evaluar y promover el debate sobre el marco ideológico y sobre el repertorio de acciones disponibles. Así, Marina Sitrin (2012) reconoce en su análisis los factores emocionales que influyen en la implicación y en el funcionamiento de los movimientos sociales. El aprecio y la confianza de los participantes entre sí son valores cruciales en las interacciones de los colectivos. Estos dos factores influyen en el fortalecimiento de los lazos en el movimiento social, en la identificación de las personas con los compañeros y en el marco ideológico del movimiento en cuestión.

\section{RESULTADOS Y DISCUSIÓN}

En el análisis de las entrevistas se identificó el proceso de construcción de un relato justificativo del uso de la desobediencia civil y de la legitimidad de la citada campaña. En este apartado se irán detallando algunos de los aspectos más relevantes del análisis del discurso.

En primer lugar, las personas entrevistadas se presentaban como ciudadanos comunes que se habían visto afectados por el contexto de crisis y que en su imaginario no esperaban vivir jamás esta situación. De este modo apelaban frecuentemente a la empa- tía con el resto de los ciudadanos de clase media o baja, cuyo estatus socioeconómico hasta hace poco compartieron. En su discurso explicitan una autopercepción notoriamente dispar con respecto a los movimientos okupa.

Los entrevistados citaban un sueldo digno, la ausencia de deudas y el hecho de regentar un pequeño negocio como características acreditativas de personas cumplidoras con el deber de ciudadanía y poseedoras de una autonomía económica. No obstante, la aparición de dificultades económicas en su vida, como la pérdida del trabajo, la separación del cónyuge o la aparición de una enfermedad que les impedía trabajar (por citar tres de las más frecuentes) había hecho que perdieran la estabilidad y empezaran a tener incumplimientos con los pagos de la hipoteca y con otros gastos básicos. Reiteraban que no se habían podido imaginar que les cambiaría la vida de esta manera, e incluso que se arrepentían de haber acometido ciertos gastos cuando las cosas les iban bien:

"No me había imaginado nunca que tendría que ocupar porque mi padre trabajaba en una empresa en Sallent, era un encargado, cobraba 3.000 euros... por eso es mucho más difícil que bajes. Estás muy arriba. Ahora no trabaja ninguno de los cinco" (Abdelhali).

La responsabilidad de tener hijos conviviendo con los entrevistados era una de las razones que identificaban como determinantes para participar en la campaña de la $\mathrm{PAH}$, ya que sentían el deber moral y legal de evitar que durmieran en la calle:

"Si fuera yo sola en la calle, no pasaría nada. Si fuera con mis hijos es otra cosa. Mis hijos son pequeños aún, la mayor tiene trece años, la segunda nueve años, después uno de ocho años. Y Hannan tres años" (Abbie).

"Si no tengo sitio donde ir, tengo que ocupar, no puedo dormir en la calle con mis hijos y la mañana siguiente los servicios sociales me quitan a mis hijos" (Fatou).

Aparte de tener un techo, aspectos relacionados con los beneficios individuales son citados también por los informantes en términos de políticas afectivas (Sitrin, 2012), como la sensación de seguridad y de una red de contactos, o elementos de carácter más logístico como el soporte legal y la facilidad en la negociación de un alquiler.

Sanae explicó que ella, junto con sus hijos y su marido, había pagado a unas personas para que les abrieran un piso que era supuestamente del banco. Pero al 
cabo de pocos días, les llamaron informándoles que el piso tenía una orden de desahucio y que se tenían que ir. Ella mencionaba que "el hecho de ocupar con la PAH hace que tengas menos miedo. Sientes que estás protegida y no estás sola".

Gladys había ocupado por su cuenta antes de conocer la PAH y narraba así su experiencia:

"Aquí en esta ocupación [refiriéndose a la de la PAH] no estás solo, es una acción colectiva, somos mucha gente. Además, tú aprendes que, si cuelgas un cartel anunciando que estás dentro, la policía no puede entrar. También te puedes empadronar con esta dirección en el ayuntamiento. Antes de vivir aquí, ocupé por mi cuenta y estaba muy muy asustada. Entré en la casa a las 3 de la noche, y no salí en dos días porque pensaba: «¿y si me vienen los vecinos o la policía?»" (Gladys).

Haber sido engañados a la hora de adquirir una hipoteca por personas en las que tenían confianza también es citado reiteradamente entre las personas entrevistadas, confirmando la hipótesis de Contreras Jiménez de que se contrae la hipoteca sin tener un conocimiento técnico adecuado.

"Mi director de banca me dijo que yo aseguraba el futuro de mis hijos porque me quedaba con el otro piso, me subrogaron una hipoteca que era de mi ex marido, que solo se debía en ese momento 28.000 euros. Pero claro... dónde llegó mi ignorancia cuando me incluyeron los adeudos de él: hacienda, embargos de hacienda, de tráfico, de las comunidades, retrasos que tenía de la empresa que él tenía..." (Carmen).

"Yo en ese momento confiaba mucho en mi expareja y en mi director de caja. Mi director de caja era una persona de buen trato, que yo siempre había confiado. Él me decía que yo era una persona que sabía pensar, que como los niños iban creciendo... pues esto era para su futuro. Yo no sabía en lo que me metía" (Carmen).

En este sentido, los interlocutores destacaron que la PAH les sirvió como empoderamiento individual y como adquisición de consciencia de sus derechos $y$ obligaciones como ciudadanos y especialmente en materia financiera (McAdam y Snow, 1997).

"La experiencia de la PAH me gusta, estoy estudiando muchas cosas, llevo aquí [en Cataluña] muchos años y nunca sabía tanto sobre derechos. Ahora sé cuales son mis derechos, antes no lo sabía, estaba como si viviera en otro mundo. Ahora gracias a Dios he aprendido muchas cosas. Antes, cuando yo iba por los sitios me ponían muchas tonterías en la cabeza, lo aceptaba y me iba a mi casa. Pero yo ahora sé que hay algunas cosas que tengo que enfrentar" (Fatou).

Uno de los aspectos cruciales en la construcción del relato en torno a la obra social de la PAH es la reiteración por parte de las personas afectadas de la voluntad de regularizar su situación de ocupación hacia el pago de un alquiler, pero un alquiler asequible según sus ingresos. Las razones más mencionadas para explicar la necesidad y la voluntad de pagar un alquiler eran, por un lado, la seguridad de tener un contrato legal y así dejar de cometer una ilegalidad y, por otro lado, cumplir con el deber moral de pagar por el uso de una vivienda.

"Aquí estamos bien. Lo que me preocupa es el trabajo. Si uno de los dos encuentra trabajo, buscamos directamente un piso de alquiler y dejamos este piso. Así tendría mi contrato, una cosa mía. Ahora me siento que tengo piso y no tengo piso" (Hafida).

En el caso de los informantes de Blanes la existencia de un contador social impulsado por el área de servicios sociales del ayuntamiento y la empresa de agua era mencionada como prueba de que tenían voluntad de pagar un precio adaptado a su nivel adquisitivo.

"Nosotros no queremos ocupar y no pagar, no. Queremos un alquiler social, que a lo que ganamos nosotros podamos pagar. $Y$ nosotros no queremos ser okupas, y hemos puesto un contador social de agua" (Juan).

También se encontraron dos casos ligeramente diferentes, ya que estos expresaron la voluntad de tener un alquiler social, pero mencionaron que no tenían interés por regular su situación en aquel momento ya que, debido a su inestabilidad económica, temían no poder pagar el alquiler social y ser desahuciados nuevamente.

"Yo no estoy negociando con el banco ni los voy a ir a buscar. Si firmas un alquiler solidario y te estás tres meses sin pagar te pueden echar. Que vengan ellos y negociemos una cantidad. Yo ahora en verano voy a estar cobrando $800 . . .900$ euros y con eso me tengo que organizar todo el año. No voy a pagar 700 euros entre alquiler, agua y luz... y quedarme con 200 euros para comer. ¡No! Mi intención es que ellos vengan, no vamos a ir nosotros a buscarlos" (Raúl).

Aquellos interlocutores que ya estaban pagando un alquiler expresaban su conformidad, pero albergando cierta desconfianza respecto al cumplimento del período de cinco años que se les había concedido.

Otro aspecto que muestra su inexperiencia en ocupaciones y su voluntad de ser "buenos ciudadanos" es 
el caso de dos mujeres que destacaron haber tenido sentimientos de vergüenza y culpabilidad durante las ocupaciones. En un caso, la persona pensaba que el resto de vecinos del edificio que no estaban ocupando la miraban mal, porque ella no estaba pagando los suministros ni el alquiler. En el otro caso, Carmen se sentía avergonzada porque creía que estaba utilizando un piso que no era suyo:

"A mí la desobediencia civil me costó, los primeros días que vivía en el bloque ocupado, yo me moría de la vergüenza, entraba corriendo. Pero un día el niño me dijo «mamá, esta es nuestra casa». Yo me les quedé mirando y vi que tenía que aprender mucho de mis hijos, ellos lo vivían como felicidad, ellos ya no vivían en el salón o en el sofá de nadie. Después dije: «ia la porra los complejos!» Y además mi objetivo era el alquiler social, lo que teníamos que hacer era presión al banco" (Carmen).

Paralelamente a la voluntad de ser inquilinos formales que, como hemos visto, se desarrolla conjuntamente con la reivindicación de unos precios accesibles, también se subrayaba la necesidad y la voluntad de encontrar un trabajo como medida de sustento. No obstante, los entrevistados de alrededor de 50 años mostraban ciertas dudas sobre la posibilidad de encontrar trabajo, comparándose con personas jóvenes supuestamente más preparadas.

"Yo había trabajado en la construcción, en el matadero, en una empresa de cables. De lo que me salía. Pero ahora no sale nada. ¿A mi edad ahora? Si no encuentran mis hijos que tienen 22 y 18 . Mi mujer tampoco encuentra trabajo. Quizás ella encuentra a lo mejor por un mes, por una semana..." (Luis).

Dos personas entrevistadas señalaron incluso que las ayudas provenientes de la asistencia social sin una obligación de trabajo a cambio les hacían sentir inútiles y, en un caso, no estar trabajando contradecía el objetivo por el cual su familia había venido a Cataluña.

“Pienso que el gobierno debería generar trabajo. Te dan una ayuda de 400 euros, pero eso lo que hace es hundirme, me estás dando 400 euros por estar en el sofá. Eso no lo veo yo bien... Yo prefiero trabajar y ganarme un dinero, no estar como un inútil" (Abdelhali).

En concordancia con la categoría de Pruijt (2004) de ocupación debida a la pobreza, la mayoría de los informantes constatan la diferencia entre el tipo de ocupaciones en las que participan y el movimiento okupa en Cataluña, que afirman haber visto por la televisión o en su propia ciudad, en el caso de Man- resa. Los informantes que se expresaron en este sentido (doce de diecinueve) se distanciaron alegando principalmente cuatro argumentos: que las ocupaciones de la $\mathrm{PAH}$ eran pacíficas, que predominaban las familias, que no habían tenido otra opción que ocupar y que era una situación temporal. El movimiento okupa era categorizado mayoritariamente como "jóvenes radicales", que en ocasiones pueden consumir drogas y que en algunos casos utilizan la violencia física. Estas dos citas seleccionadas ilustran la distancia percibida:

"A mí nunca me gustó la idea de ocupar pisos porque para mí es como robar. Cuando estaba viviendo en la calle San Ramón había jóvenes de veinte años ocupando pisos. Entran cuando quieren y salen cuando quieren, fuman, gritan... No me gustan. Pero cuando una familia tiene que salir a la calle con tres niños o con un niño... es muy duro. Por eso yo... si encontramos trabajo alquilamos un pisito y así podremos seguir adelante. Hay que luchar" (Hafida).

“El problema es que aquí en Cataluña el movimiento okupa está muy mal visto, porque la gente los ve como los típicos porretas que pasan de todo, que entran en un piso y viven la vida. Y no es así ahora, en estos momentos no, hay familias... parejas que no pueden pagar ni hipoteca ni piso... y tienen que ocupar" (Rosa).

Una persona afirmó desconocer el movimiento okupa de Cataluña, pero mencionó haber escuchado el caso de Can Vies ${ }^{9}$ en Barcelona y su resistencia, y añadió que las personas que ocupan lo hacen por necesidad y que suponía que este colectivo también tenía sus necesidades. Por otro lado, el portavoz entrevistado de la campaña la obra social de la PAH en Cataluña mostró una opinión diferente al resto de los entrevistados. Su opinión se podría enmarcar en el marco teórico de Tilly (1986), dado que apuntaba similitudes y diferencias entre los dos tipos de ocupaciones, debido al contexto histórico y político. A su parecer, sí había diferencias entre los dos tipos de ocupación, pero también puntos en común, dado que las ocupaciones de la PAH habían heredado ideas y conocimiento del movimiento okupa de Cataluña, como sustentan Mir García et al., (2013):

"En el caso de Sabadell, no es un colectivo de afectadas quien empezó, sino que es gente politizada, que viene del movimiento okupa y la lucha por una vivienda digna, quien ve la necesidad y apuesta por formar un poco a ciegas un núcleo de la PAH, y desgraciadamente, debido a la dramática situación social, tiene éxito y viene mucha gente" (Martí). 
No obstante, Martí también hizo constar diferencias tanto en el tipo de acción como en la comunicación, ambas facilitadas por el contexto de crisis hipotecaria. En la obra social se había puesto mucho énfasis en la justificación y comunicación del uso de la desobediencia civil (Rawls, 1971) para ganar legitimidad ante el vecindario, ante la opinión pública y también frente al sistema judicial en caso de juicio. Otra diferencia identificada por el portavoz es el contacto y predisposición para negociar con la administración pública y con los bancos para conseguir la regularización del alquiler.

"A diferencia de hace cinco años, cuando alguien ocupaba, la BRIMO ${ }^{10}$ te metía tortas y te reventaba, y la gente te miraba como si fueses un cerdo y un perroflauta. Y ahora la gente ha cambiado la percepción, la PAH ha conseguido cambiar la valoración, ha ido acumulando legitimidad sin prisa" (Martí).

La consecución de acciones de protesta previas al uso de la desobediencia civil (Rawls, 1971) está presente en el discurso de los entrevistados. La presentación de la campaña de la obra social de la PAH se explicaba en relación con las otras campañas precedentes, como son Stop desahucios, ILP por el derecho a una vivienda digna, con las presiones a los bancos para negociar daciones en pago y alquileres sociales:

\footnotetext{
“Primero aquí en la PAH trabajamos por conseguir firmas para la ILP, para conseguir, entre muchas otras cosas, la regulación de la dación en pago. Pero no nos escucharon. También hemos estado activas con parar desahucios, concentrándonos delante de las casas, hemos hecho manifestaciones dentro de bancos. Pero, aun así, no hemos solucionado el problema, la gente sigue sin tener dónde ir cuando la desahucian, entonces solo nos queda ocupar. Y así lo explicamos, hemos luchado en todos los otros aspectos y ahora tenemos que dar solucionar a las personas que no tienen donde dormir" (Teresa).
}

Asimismo, de acuerdo con Pruijt (2004), la titularidad de los edificios es significativa en la ocupación debida a la pobreza, ya que, si la entidad propietaria del edificio es un actor con responsabilidad social, se incrementa la legitimidad que puede generar la ocupación y la empatía en la población. En el caso estudiado, los inmuebles pertenecen a algún banco o a la SAREB, los ocupantes lo comprueban previamente en el registro de la propiedad. De esta manera se denuncia la existencia de pisos que no cumplen con su función social (Sabaté, 2014). En esta cita Eugenio refleja su percepción sobre la titularidad de los edificios ocupados:
"El hecho de que los edificios ocupados sean propiedad de los bancos y de la SAREB te legitima. Para mí los tendrían que poner en alquiler, están perdiendo dinero. Han estado acumulando a costa de la gente de este país, han estado especulando" (Eugenio).

En la construcción del relato también tiene un papel crucial el Estado que, en el caso de los entrevistados, es representado a través de las oficinas de servicios sociales municipales. Todos los informantes, excepto el portavoz, estaban en contacto con el área de servicios sociales y algunos con otras áreas, como alcaldía o vivienda.

Las personas entrevistadas habían intentado encontrar soluciones a través de servicios sociales en forma de ayuda económica o vivienda social. En general, la opinión con respecto a la administración pública local era negativa, de ineficiencia, de excesiva burocratización e incapacidad resolutiva. Los ejemplos más comunes destacan la incapacidad de ayudarlos cuando tenían problemas con la hipoteca, incluso se constata que algunas trabajadoras sociales enviaban a los afectados a la PAH para que les ayudaran con la negociación de la deuda o la dación en pago. La otra principal demanda de los entrevistados a los servicios sociales era la vivienda social, dado que, en todos los casos excepto en uno, nunca se les había ofrecido una vivienda, alegando sus bajos ingresos (incapacidad de asumir los costes) o debido a la lista de espera para entrar en esta (exceso de demanda):

"Cuando estaba pendiente del desahucio fui a la trabajadora social y me dijeron que con mis ingresos del paro no tenía acceso a un piso de protección oficial. Me tramitaron para que recibiera comida de una ONG local y ya está. No te dan soluciones allí" (Gladys).

"Cuando vas a servicios sociales te contestan: «ven mañana, a lo mejor te ayudamos»... y otro y otro día. No te dan soluciones" (Juan).

El portavoz entrevistado añadía a las críticas a la administración pública la ausencia de liderazgo y las carencias en la garantía de derechos básicos, como es el derecho a la vivienda. Apuntaba que la PAH realizaba negociaciones con los bancos para conseguir alquiler social, daciones en pago etc. de los afectados, y que en estas negociaciones raramente acudían representantes de la administración pública a dar soporte o para liderarlas.

Como se ha apuntado, entre los entrevistados había una excepción en materia de vivienda social. A Luís y a su familia (ocho personas en total) les ofrecieron dos pisos de protección oficial que rechazaron 
por no tener suficiente tamaño, en un caso, y en el otro porque estaba demasiado lejos de donde habían construido sus redes sociales.

Un aspecto que se reconocía como positivo de la relación de los entrevistados y los servicios sociales era la redacción de informes alegando que su situación era de emergencia social, que en caso de juicio adquirían valor, puesto que podían presentarse para justificar la ocupación:

"La juez fue valiente y les denegó la solicitud de desalojo cautelar que presentó SAREB. Hubo una interlocutoría que venía a decir que SAREB no tenía ninguna urgencia en recuperar la propiedad, que la urgencia la tenían las familias que habían demostrado a los juzgados con informes de servicios sociales que no tenían dónde ir ni suficientes ingresos para alquilar" (Martí).

También en las entrevistas mencionaron como positivo el ambiente y las relaciones que se establecen en los edificios ocupados colectivamente, percibidos como un espacio de ayuda mutua y sentido de comunidad (Sitrin, 2012). Entre las interlocutoras que habían vivido en el bloque de Salt, el sentimiento de comunidad se extendía y era recordado como algo diferencial de la experiencia. Una de las mujeres destacó que el bloque de Salt era una experiencia que sobrepasaba la lucha por el derecho a la vivienda, creando vínculos comunitarios y de empoderamiento entre mujeres:

"Cuando finalmente nos comunicaron que se realojaría a las personas que vivían al bloque que cumpliesen los criterios, nos negamos porque lo que nosotras queríamos era seguir viviendo juntas. Aquí las mujeres nos organizábamos para cocinar, para cuidar de los niños, para limpiar, pero también para luchar, para luchar contra el capitalismo que permite que se salven los bancos y no las personas. Y eso no queríamos perderlo. Fuimos felices aquí" (Dinora).

En el caso de las informantes del bloque de BarceIona, comentaron que al principio la convivencia fue un poco difícil, por la organización de la limpieza y porque no tenían la misma situación personal y familiar, pero a lo largo del año que estuvieron en el bloque mejoraron la coordinación:

"Al principio era duro, tuvimos problemas, no es fácil tratar de convivir. Compartimos una zona comunitaria por la cual hacíamos una reunión quincenal. Hubo rifirrafes porque uno decía «que tú limpias menos, que tú limpias más». Lo típico de una comunidad. Después de todo fue una experiencia muy bonita, que son gente muy buena" (Carmen).

\section{CONCLUSIONES}

Cuando se establecieron los cimientos de esta investigación en 2014 ya se intuía el liderazgo de la PAH en la reivindicación del derecho a la vivienda, en el uso de la desobediencia civil y en la movilización de las personas afectadas, aunque difícilmente podía anticiparse su impacto. El presente artículo se ha centrado en los discursos legitimadores de la desobediencia civil y los resultados aportan información para la comprensión de las estrategias de protesta desarrolladas desde 2008 en la sociedad catalana y española.

En los análisis de las entrevistas se observó la construcción del discurso justificativo de la desobediencia civil, con los diferentes aspectos característicos apuntados por Rawls (1971): acciones previas de protesta, comunicación de la campaña, acatamiento de las consecuencias de la desobediencia. El contexto histórico y político es también un elemento que hay que tener en consideración, condicionador del tipo de acción que hay que seleccionar en toda protesta y de su configuración (Tilly, 1986). Con esta base, se constata que la categorización del fenómeno de las ocupaciones de inmuebles de Pruijt (2004) permite comprender la diversidad del movimiento, y asimismo entender que la ocupación debida a la pobreza es reproducible y, de hecho, se ha producido en otros países europeos en diferentes épocas.

No obstante, este artículo permite apuntar las relevantes especificidades de las ocupaciones en la campaña la obra social de la PAH y entender más profundamente este fenómeno a partir del análisis de la vivencia de los participantes y de la correspondiente interpretación de la desobediencia civil. El análisis desarrollado confirma que las personas que se han visto forzadas a ocupar por carencia de una alternativa habitacional y que no habían participado antes en reivindicaciones se esfuerzan en legitimar la desobediencia civil, su condición de buenos ciudadanos y la temporalidad de la acción. Paralelamente el discurso del portavoz, con una trayectoría de activismo previa, se centra más en resaltar las aspiraciones políticas de la campaña, apuntando la influencia de las ocupaciones políticas en la campaña la obra social de la $P A H$. Los resultados de este estudio cualitativo ponen de relieve que la clasificación de Pruijt (2004) de ocupación debida a la pobreza confirma su validez y vigencia, aunque estas categorías no son herméticas y se pueden trazar similitudes y influencias entre ellas.

De esta manera, la crisis hipotecaria, la acción del estado y de los bancos, y la acumulación de legitimidad 
por parte de la PAH en la sucesión de anteriores campañas crean un contexto para que la campaña la obra social de la $P A H$ pueda ser desarrollada, a pesar de que la mayoría de los participantes sean personas que no se habían involucrado previamente en reivindicaciones políticas. El discurso legitimador, las pequeñas victorias tangibles (por ejemplo, conseguir alquileres asequibles para los ocupantes) y los aspectos internos de los grupos de ocupantes relacionados con la seguridad, el soporte y la ayuda mutua (Sitrin, 2012) forman parte del éxito y de la continuidad de la campaña.

Finalmente, el presente artículo apunta a nuevas direcciones de investigación, como la continuidad de la implicación de las personas con la PAH después de haber conseguido el alquiler social, la influencia que los cambios en el contexto económico y político en el nivel estatal, autonómico o local puedan tener en las estrategias de la PAH, y la evolución futura de la situación económica y social de las personas que han participado en la $\mathrm{PAH}$.

\section{AGRADECIMIENTOS}

Mi sincero agradecimiento a Pau, Irene y Ábel por sus sugerencias, y a las personas entrevistadas por su predisposición.

\section{NOTAS}

[1] El texto del artículo 47 dice: "Todos los españoles tienen derecho a disfrutar de una vivienda digna y adecuada. Los poderes públicos promoverán las condiciones necesarias y establecerán las normas pertinentes para hacer efectivo este derecho, regulando la utilización del suelo de acuerdo con el interés general para impedir la especulación. La comunidad participará en las plusvalías que genere la acción urbanística de los entes públicos".

[2] La ILP también proponía aumentar los alquileres sociales de los pisos vacíos propiedad de los bancos y demorar los desahucios por cuestiones económicas. Se consiguieron en torno a 1.500.000 firmas de ciudadanos españoles.

[3] El nombre de esta campaña hace referencia a la obra social de la Caixa,

\section{BIBLIOGRAFÍA}

Alguacil Denche, A., Alguacil Gómez, J., Arasanz Díaz, J., Fernández Evangelista, G., Paniagua Caparrós, J. L., Olea Ferreras, S. y Renes Ayala, V. (2013). La vivienda en España en el siglo XXI. Diagnóstico del modelo residencial $y$ propuestas para otra política de vivienda. Madrid: Fundación Foessa / Cáritas Española Editores.

Cabré Pla, A. y Módenes Cabrerizo, J. A. (2004). Home Ownership and Social Inequality in Spain. En Kurtz, K. y Blossfeld, H.-P. (eds.). Home Ownership and Social Inequality in Comparative Perspective. Stanford: Stanford University Press, pp. 233-254. entidad con fines sociales que pertenece a CaixaBank, banco que ha protagonizado ejecuciones hipotecarias terminadas en desahucio.

[4] La Generalitat tiene competencia en materia de vivienda. En 2007 se aprobó la llei de l'habitatge.

[5] La SAREB es una entidad financiera creada en 2012 con capital público y privado para gestionar los "activos tóxicos" de los bancos españoles.

[6] Por alquiler social se entiende una cantidad que hay que pagar por un inmueble que se sitúa por debajo de los precios del mercado y se establece teniendo en cuenta la situación económica de la familia.

[7] Es decir, de forma no vinculada a la campaña de la PAH y sin el objetivo de reivindicar un alquiler social.
[8] Desde un análisis marxista, la plusvalía es el beneficio obtenido de la diferencia entre el valor económico de aquello producido y el salario percibido por los trabajadores.

[9] Can Vies, en el barrio de Sants de Barcelona, es un Centro social okupado (CSO) desde 1997, que en 2014 fue desalojado por parte del Ayuntamiento de dicha ciudad, provocando un episodio de protestas extendidadas a toda la ciudad que terminó con el paro del desalojo y la posterior reocupación del edificio.

[10] Brigada móvil de los Mossos d'Esquadra. Se trata de un cuerpo de la policía especializado en mantener el orden en las vías públicas donde se concentran masas de personas.
Gamson, W. A. (1992). Talking politics. Cambridge: Cambridge University Press.

Harvey, D. (2012). Rebel cities. From the right to the city to the urban revolution. London / New York: Verso

Lefebvre, H. (2013). La producción del espacio. Madrid: Capitán Swing.

McAdam, D. y Snow, D. A. (eds.) (1997). Social Movements: Readings on Their Emergence, Mobilization, and Dynamics. Los Angeles, Calif: Roxbury Publishing Company.

Mir García, J., França, J., Macías, C. y Veciana, P. (2013). Fonaments de la
Plataforma d'Afectats per la Hipoteca: activisme, assessorament collectiu i desobediència civil no violenta. Educació Social. Revista d'Intervenció Socioeducativa, 55, pp. 51-60.

Naredo, J. M. (2009). La cara oculta de la crisis. El fin del boom immobiliario y sus consecuencias. Revista de Economía Crítica, 7, pp. 313-340.

Palomera, J. (2014). How Did Finance Capital Infiltrate the World of the Urban Poor? Homeownership and Social Fragmentation in a Spanish Neighbourhood. International Journal of Urban and Regional Research, 
38 (1), pp. 218-235. https://doi. org/10.1111/1468-2427.12055

Pareja Eastaway, M. y Sánchez Martínez, M. T. (2012). La política de vivienda en España: lecciones aprendidas y retos de futuro. Revista Galega de Economía. 21 (2), pp. 1-32.

Pruijt, H. (2004). Okupar en Europa. En Adell Argilés, R. y Martínez López, M. A. (eds). ¿Dónde están las llaves? El movimiento okupa: prácticas y contextos sociales. Madrid: Catarata, pp. 35-60.

Rawls, J. (1971). A Theory of Justice. Cambridge, MA: Harvard University Press.

Sabaté, I. (2014). What If We Fail to Pay the Mortgage? Thinking the Unthinkable in a Country of Homeowners. [En línea]. Disponible en: https://www. academia.edu/6127014/What_if_we fail_to_pay_the_mortgage_Thinking_ the_unthinkable_in_a_country_of_ homeowners

Sassen, S. (2012) Expanding the Terrain for Global Capital: When Local Hous- ing Becomes an Electronic Instrument. En Aalbers, M. B. (ed.) Subprime Cities: The Political Economy of Mortgage Markets. Malden MA: Wiley-Blackwell. pp. 74-96. https://doi. org/10.1002/9781444347456.ch3

Sitrin, M. A. (2012). Everyday Revolutions: Horizontalism and Autonomy in Argentina. London: Zed Books.

Tarrow, S. G. (2011). El poder en movimiento. Madrid: Alianza Editorial.

Tilly, C. (1986) The Contentious French Cambridge MA: Harvard University Press. https://doi.org/10.4159/harvard.9780674433984

\section{Otros recursos}

Cómo contactar con la PAH. [En línea]. Disponible en: https://afectadosporlahipoteca.com/contacto/

Contreras Jiménez, E. ¿Locura o decisión "racional" y económica? Ponencia presentada en el XI Congreso Español de Sociología, Julio 2013. [En línea]. Dis- ponible en http://www.fes-sociologia. com/locura-o-decisin-racional-y-econmica/congress-papers/452/

Instituto Nacional de Estadística. Encuesta de población activa. [En línea]. Disponible en: https://www.ine.es/dyngs/ INEbase/es/operacion.htm?c=Estadistic a_C\&cid=1254736176918\&menu=ultiD atos\&idp=1254735976595

Colau, A. y Alemany, A. PAH. Plataforma de Afectados por la Hipoteca. Enero 2013. 2007-2012: Retrospectiva sobre desahucios y ejecuciones hipotecarias en España, estadísticas oficiales e indicadores. [En línea] Disponible en: http:// afectadosporlahipoteca.com/wp-content/uploads/2013/02/RETROSPECTIVA-SOBRE-DESAHUCIOS-Y-EJECUCIONES-HIPOTECARIAS-EN-ESPA\%C3\%91ACOLAUALEMANY1.pdf

Poder Judicial España. Consejo General del Poder Judicial. Estadística Judicial. [En línea] Disponible en: http://www. poderjudicial.es/cgpj/es/Temas/Estadistica-Judicial/ 